\title{
90. rocznica wmurowania aktu erekcyjnego pod budowę Instytutu Radowego w Warszawie
}

Przed 90 laty - 7 czerwca 1925 roku odbyła się w Warszawie podniosła uroczystość wmurowania aktu erekcyjnego pod budowę Instytutu Radowego.

Z Paryża przybyła Maria Skłodowska-Curie. Delegacja rządowa witała ją już na granicy, a na dworcu w Warszawie — władze stolicy, mieszkańcy oraz rodzeństwo — dr Józef Skłodowski i dr Bronisława Dłuska. Wizyta trwała 10 dni, a jej program był bogaty. Uczona m.in. wygłosiła wykłady w Instytucie Francuskim i na Uniwersytecie Warszawskim, była przyjęta w Ratuszu, gdzie otrzymała honorowe obywatelstwo Warszawy, odwiedziła Towarzystwo Naukowe
Warszawskie, Politechnikę i Pracownię Radiologiczną przy ul. Śniadeckich.

Przede wszystkim jednak w dniu 7 czerwca o godz. 12.30 uczestniczyła w ceremonii przy ul. Wawelskiej. Z Belwederu nadjechał Prezydent Rzeczypospolitej Stanisław Wojciechowski. Obecny był premier Władysław Grabski, marszałkowie Sejmu i Senatu - Maciej Rataj i Wojciech Trąmpczyński, ministrowie, rektor Uniwersytetu Warszawskiego, a zarazem Prezes Towarzystwa Instytutu Radowego prof. Franciszek Krzyształowicz, elita naukowa i kulturalna.

Przytaczamy poniżej pełny tekst „Aktu erekcyjnego":

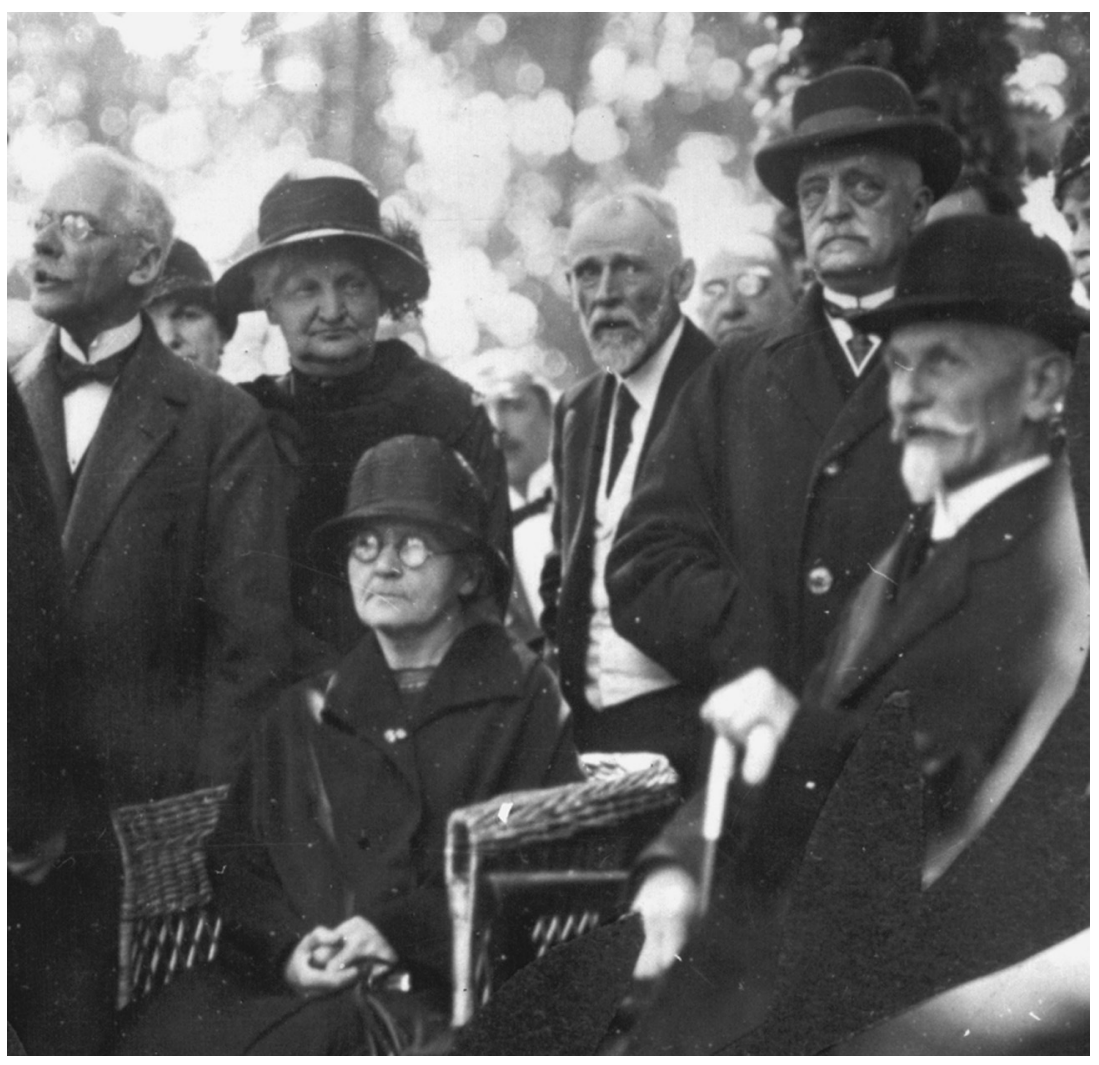

Maria Skłodowska-Curie i Prezydent Rzeczypospolitej Polskiej Stanisław Wojciechowski podczas uroczystości wmurowania aktu erekcyjnego przy ul. Wawelskiej.

Za Prezydentem stoi dr Józef Skłodowski, dalej w lewo dr Kazimierz Dłuski za Marią

— dr Bronisława Dłuska, a dalej w lewo — prof. Franciszek Krzyształowicz,

Rektor UW i Prezes Towarzystwa Instytutu Radowego 


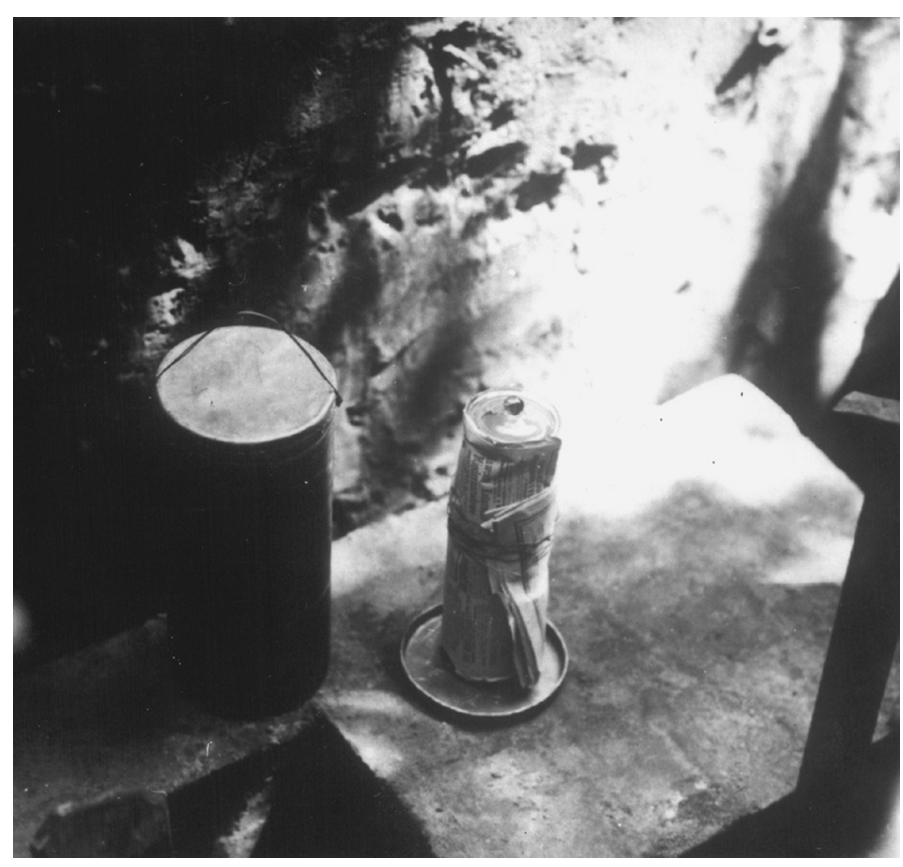

Akt erekcyjny i metalowa puszka

przygotowane do wmurowania w fundament Instytutu

„Działo się to w dniu siódmym miesiąca czerwca Roku Pańskiego Tysiąc Dziewięćset Dwudziestego piątego, a ósmego od czasu przywrócenia niepodległości Polski po wielkiej wojnie narodów — gdy godność Prezydenta Najjaśniejszej Rzeczypospolitej piastował Stanisław Wojciechowski, Roku dwudziestego ósmego od czasu wiekopomnego odkrycia nowego pierwiastka Wszechmaterji - Radu przez genjusz uczonej Polki i Jej towarzysza pracy i męża Piotra Curie, która w dobie niewoli i opresji Narodu znalazła wdzięczne pole do pracy we wtórej Ojczyźnie we Francji

Wobecności Najwyższych Dostoinikow:

Prezydenta Rzeczypospolitej - Stanisława Wojciechowskiego. Prezesa Ministrów — Władysława Grabskiego. Ministra Wyznań Religijnych i Oświecenia Publicznego — Stanisława Grabskiego, Marszałków Sejmu i Senatu — Macieja Rataja i Wojciecha Trąmpczyńskiego, w obecności Marji Skłodowskiej Curie. Rektora Uniwersytetu Warszawskiego i Prezesa Towarzystwa Instytutu Radowego Franciszka Krzyształowicza, Członków Komitetu Daru Narodowego dla Marji Skłodowskie-Curie, oraz Komitetu dla zwalczania raka, przedstawicieli Nauki, Sztuki, Związków, Stowarzyszeń i wszystkich Warstw Społeczeństwa został uroczyście odczytany i podpisany mniejszy Akt Erekcyjny Instytutu Radowego imienia Marji Skłodowskiej-Curie.

Wolą Społeczeństwa powołany jest Instytut ten nie tylko do badań samodzielnych i krzewienia w Polsce nauki o ciałach promieniotwórczych, ale i do walki z rakiem - jedną z najcięższych chorób, będących klęska całej Ludzkości.

Powstaje ten Instytut z ofiar i wysiłków Ogółu Polskiego, jako Dar Narodowy dla Wielkiej Uczonej.

Po odczytaniu i podpisaniu niniejszego Aktu został on wraz z gazetami z dnia siódmego Czerwca roku bieżącego oraz ze spółczesnymi monetami umieszczony na wieczną rzeczy pamiątkę w puszce ołowianej, która złożono w fundamencie gmachu projektowanego przez Architekta Tadeusza Zielińskiego, podczas uroczystego poświęcenia przez Księdza Kanonika Antoniego Szlagowskiego profesora wydziału teologicznego Uniwersytetu Warszawskiego.

Poczem otwór zamurowano." [1] 


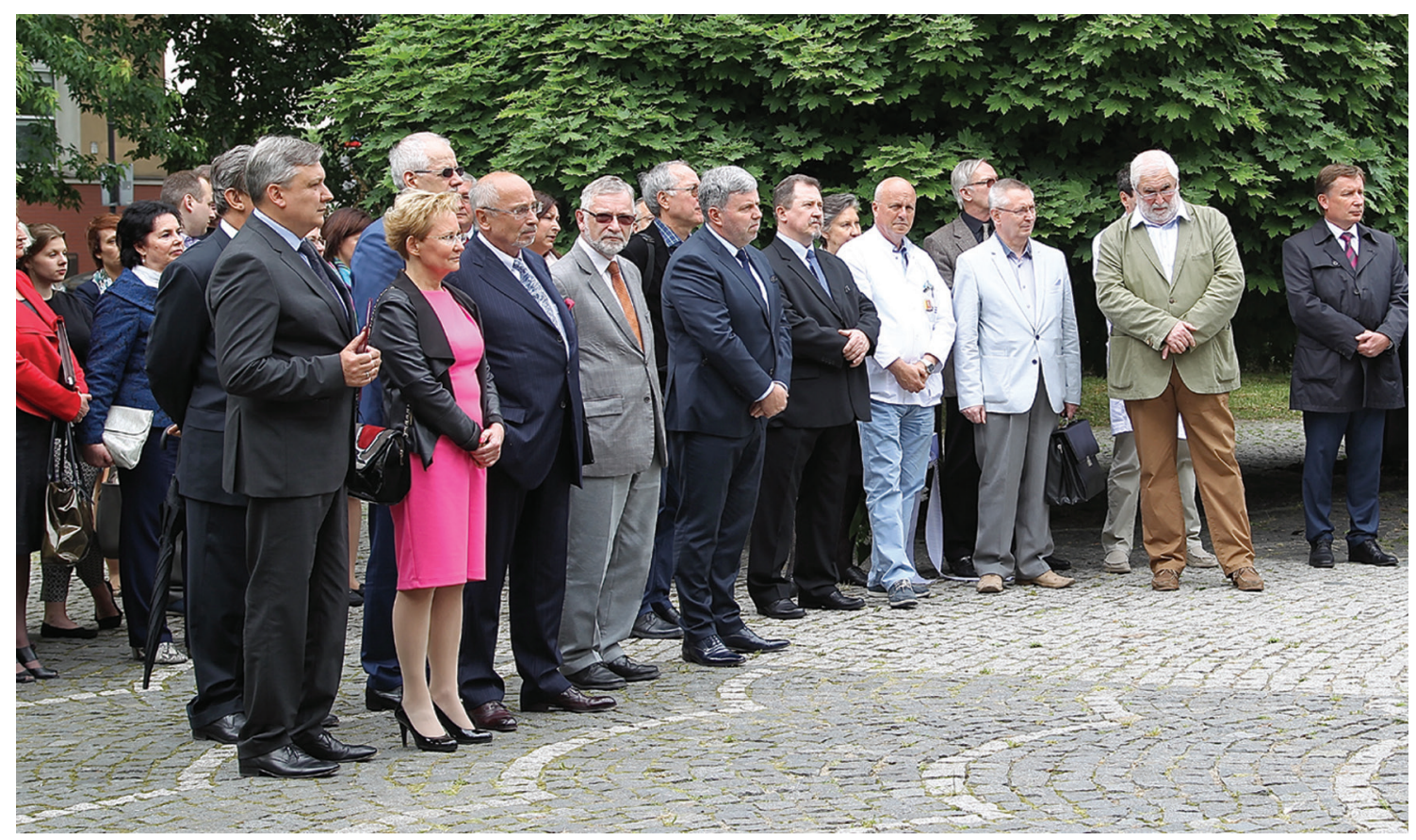

Dyrektorzy ośrodków onkologicznych i przedstawiciele pracowników Centrum Onkologii — Instytutu im. Marii Skłodowskiej-Curie podczas uroczystości

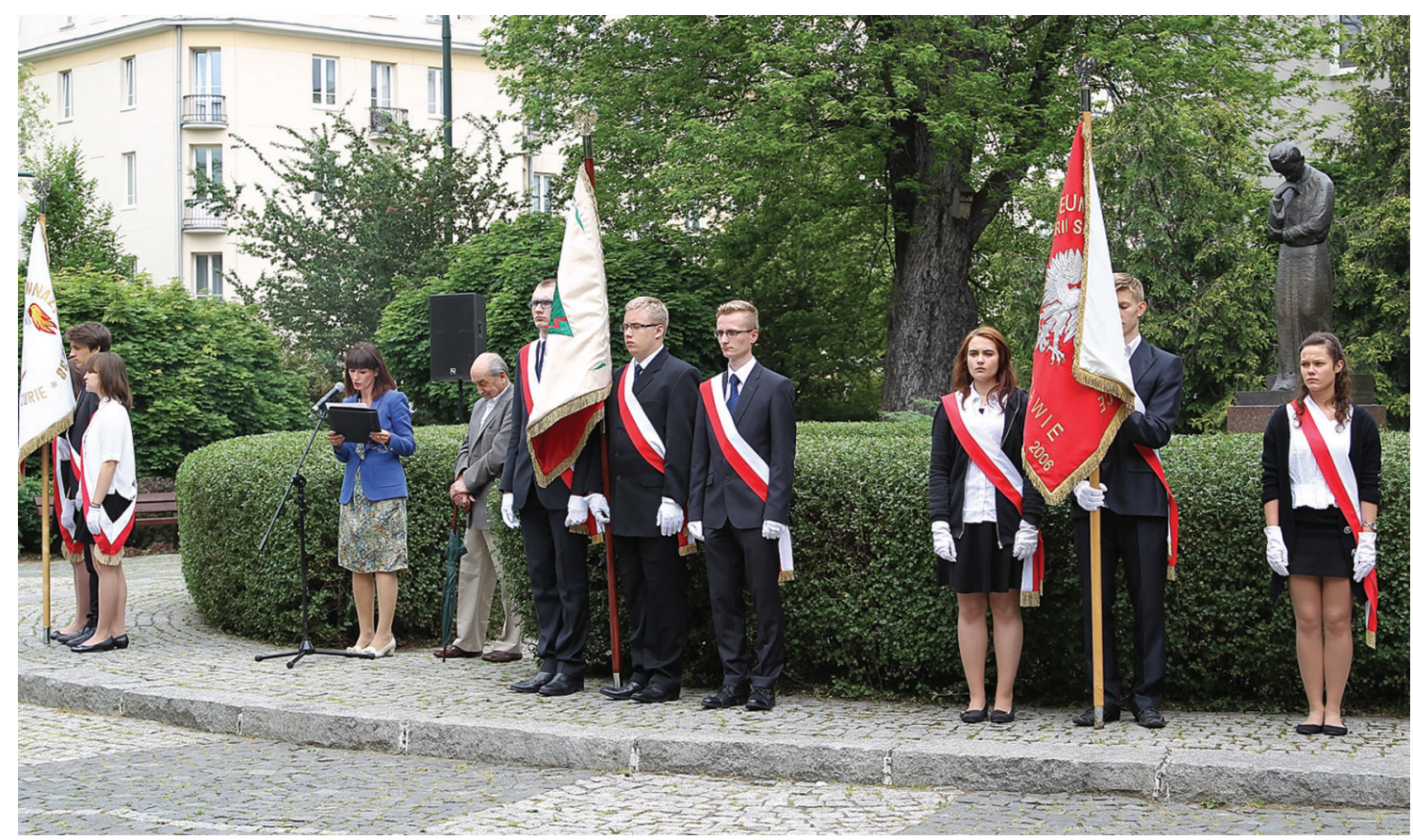

Wystąpienia Małgorzaty Sobieszczak-Marciniak — prezes Towarzystwa „Marii Skłodowskiej-Curie w Hołdzie" i prof. Andrzeja Kułakowskiego - nestora polskich onkologów pracującego w Instytucie od 1953 roku, w asyście pocztów sztandarowych

„W piękny, słoneczny poranek czerwcowy Prezydent Rzeczypospolitej kładzie pierwszą cegłę pod fundamenty Instytutu. Maria kładzie drugą — trzecią zaś prezydent $\mathrm{m}$. Warszawy" [2]. Kolejne cegły kładli obecni na uroczystości dygnitarze [3]. Poświęcenia dokonał ksiądz Szlagowski [4].
[1]. Księga informacyjna na rzecz Daru Narodowego dla Marji Skłodowskiej Curie. Warszawa 1926, s. 28.

[2]. Curie E. Maria Curie. Warszawa 1939, s. 394. Prezydentem Warszawy był wówczas Władysław Jabłoński — przyp. Red.

[3]. Księga informacyjna... op. cit. s. 20.

[4]. Józef Szlagowski (1864-1956), biskup pomocniczy archidiecezji warszawskiej, rektor Uniwersytetu Warszawskiego, niezwykle popularny wśród studentów, członek Towarzystwa Naukowego Warszawskiego, zarządu Kasy im. Józefa Mianowskiego i Zakładu Narodowego im. Ossolińskich. Był też obecny w 1932 r. podczas uroczystości otwarcia Instytutu Radowego. 


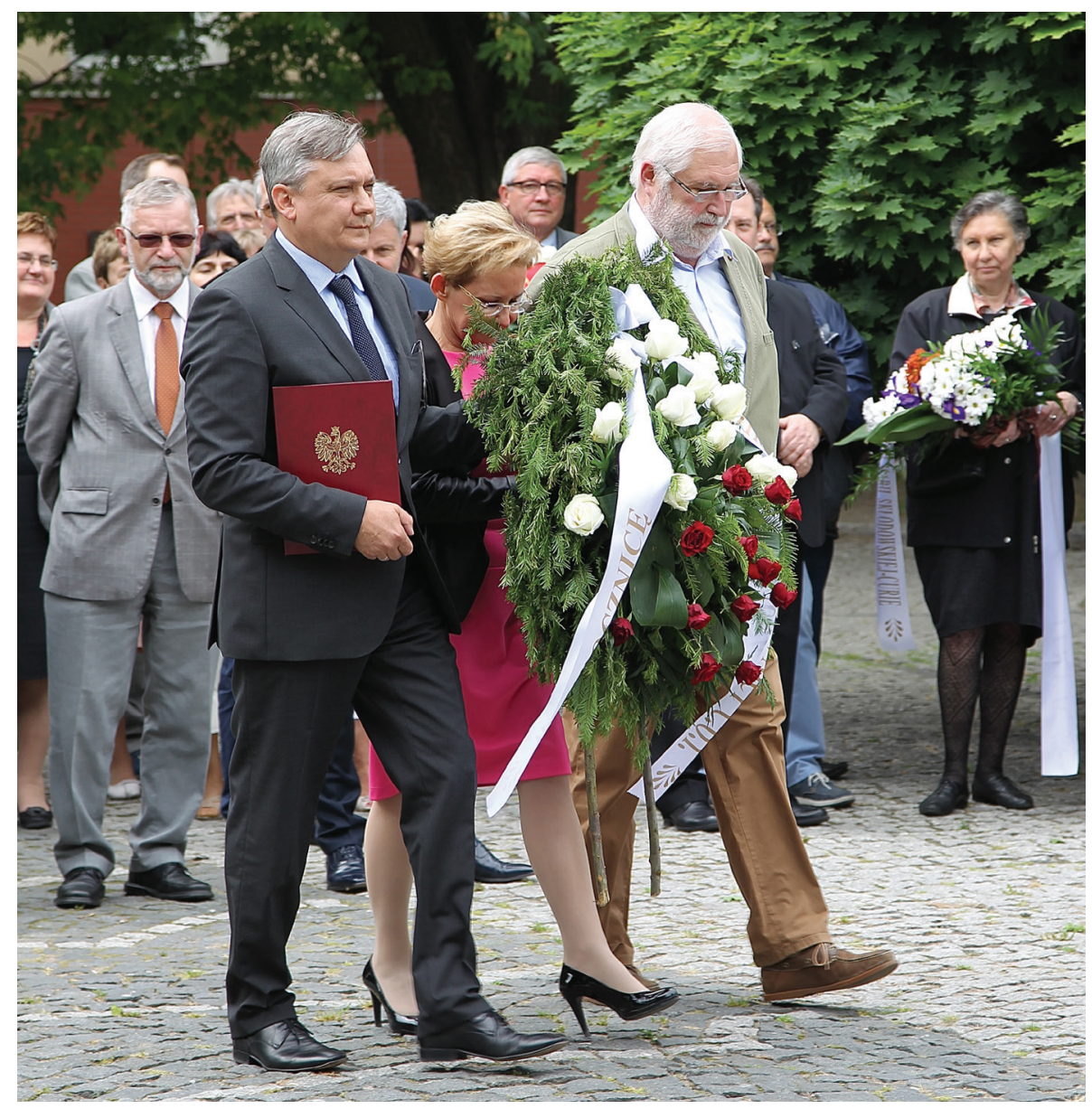

Wieniec składa prof. Krzysztof Warzocha — dyrektor Centrum Onkologii — Instytutu im. Marii Skłodowskiej-Curie w asyście wicedyrektor dr Beaty Jagielskiej i prof. Edwarda Towpika — redaktora Nowotworów

Po ceremonii Maria Skłodowska-Curie udała się na śniadanie w Belwederze wydane przez Prezydenta RP, towarzyszyło jej wąskie grono najwyższych dostojników i rodzeństwo. Pracowity dzień zakończyło wieczorne przyjęcie w Ratuszu.

Niemal dokładnie w 90 lat potem - 9 czerwca 2015 r. uroczyście przypomniano tamte ważne chwile. Pod pomnikiem Marii Skłodowskiej-Curie naprzeciwko Instytutu przy ul. Wawelskiej złożyli kwiaty: prof. KrzysztofWarzocha — dyrektor Centrum Onkologii — Instytutu im. Marii Skłodowskiej-
-Curie, prof. Andrzej Kułakowski i mgr Małgorzata Sobieszczak-Marciniak w imieniu Towarzystwa „Marii Skłodowskiej-Curie w Hołdzie", wiceburmistrz dzielnicy Ochota. W ogrodzie Instytutu młodzież szkolna pod kierunkiem Zofii Kucówny, w strojach „z epoki”, odtworzyła fragmenty przemówień wygłoszonych przed 90 laty. Organizacja uroczystości była dziełem Towarzystwa „Marii Skłodowskiej-Curie w Hołdzie”.

Redakcja Nowotworów 